\title{
Introduction: Non-state Diplomacy from Non-Western Perspectives
}

\author{
Natalia Grincheva \\ Research Unit in Public Cultures (RUPC), The University of Melbourne, \\ Parkville, vic 3052, Australia \\ natalia.grincheva@unimelb.edu.au \\ Robert Kelley \\ School of International Service, American University, Washington, DC \\ 20016-8017, United States \\ jkelley@american.edu
}

The primary ambition of this special issue of The Hague Journal of Diplomacy ${ }^{1}$ is to approach a certain segment of the diplomatic universe that has been heretofore overlooked, and yet one could argue it is also more than ever pertinent

1 Acknowledgements: This special issue of The Hague Journal of Diplomacy evolved with the assistance, support and encouragement of many distinguished academics. First and foremost, we take this opportunity to express our sincere gratitude to Professor Rhonda Zaharna. Her contribution to the development of this project is truly invaluable. She has patiently followed, advised and shaped the development trajectory of this special issue with her brilliant insights and suggestions at all stages, from initial abstract reviews to the final polishing of contributing articles. We would also like to thank Professor Jan Melissen, first for supporting the idea of this issue back in 2017, and then for investing his expertise, time and commitment to transform this idea into an exciting publication journey, all the way to its fruition. We would also like to acknowledge the contribution of all the anonymous reviewers, whose expertise in specific geographic areas has been instrumental in achieving the high quality of contributions collected herein. Finally, it is worth mentioning that the whole project would not have happened if Professor Nick Cull had not encouraged Dr Grincheva to pursue her ideas on non-Western non-state diplomacy by organising a panel for the 2017 International Communication Association (ICA) Conference. The initial call for presentations that resulted in more than 20 abstracts arriving from Asia, Africa, Eastern Europe, the Middle East and Latin America proved that the project is relevant and, even, urgent. As pleased as we are with the results, we also hope that this marks the beginning of a new phase of knowledge focusing on non-state diplomacy to illuminate pathways for future research. We are very grateful to everyone who helped us to take this important step forwards, to better understand such a phenomenon as non-state diplomacy. 
to the effort to understand geopolitical and cultural impacts on governance in contemporary diplomacy. ${ }^{2}$ The articles that form 'Non-State Diplomacy from Non-Western Perspectives' are foremost joined by their challenge to two prevailing tendencies in diplomatic studies scholarship: first, the interpretation of non-Western practices through a predominantly Western lens; and, following from this, that diplomatic action in these contexts is largely confined to state institutions.

Each of the articles in this special issue applies exploratory lenses of 'contextual discovery' to recalibrate foundational developments in the current diplomacy scholarship through an empirical research conducted in non-Western countries. ${ }^{3}$ Each article offers fresh findings from non-Western contexts to enrich a growing body of literature that takes a 'post-globalist' approach to the study of diplomacy. ${ }^{4}$ In doing so, the scholarship embraces complexities of challenging co-existence among state and non-state actors in the field of international relations. Two years in the making, this special issue expresses our hope that - by drawing these perspectives into the light — we will be in a much better position to meet this non-state/non-Western phenomenon with a fuller appreciation of its manifestations.

\section{Defining 'Non-state' Diplomacy}

To initiate such an exploration, the body of works in this issue relies on the findings of recent public diplomacy scholarship that takes a 'post-globalist' approach. It argues that growing globalisation and acceleration of informational flows make the international conduct of contemporary diplomacy more transparent. As a result, this new order allows a variety of players to gain access to information and resources, bringing in new actors of diplomacy. ${ }^{5}$ Even

2 Noé Cornago, Plural Diplomacies: Normative Predicaments and Functional Imperatives (Leiden: Brill, 2013).

3 Jong Kun Choi, 'Theorizing East Asian International Relations in Korea', Asian Perspectives, vol. 32, no. 1 (2008), pp. 193-216.

4 See Brian Hocking, 'Non-State Actors and the Transformation of Diplomacy', in Bob Reinalda (ed.), The Ashgate Research Companion to Non-State Actors (Abingdon: Routledge, 2011); and Stuart Murray, 'Consolidating the Gains Made in Diplomacy Studies: A Taxonomy', International Studies Perspectives, vol. 9, no. 1 (2008), pp. 22-39.

5 See Joseph Nye Jr, Soft Power: The Means to Success in World Politics (New York, NY: PublicAffairs, 2004); Jan Melissen (ed.), The New Public Diplomacy: Soft Power in International Relations (New York, NY: Palgrave Macmillan, 2005); Rhonda Zaharna. 'The Soft Power Differential: Network Communication and Mass Communication in Public Diplomacy', The Hague Journal of Diplomacy, vol. 2, no. 3 (2007), pp. 213-228. 
though diplomacy remains generally state-centric, recent decades have seen a rise in non-state actors that 'have global interests and the will to make them felt on the world stage.. ${ }^{6}$ As Robert Kelley explains, since the 199os, the state monopoly on diplomacy has been steadily declining because of 'expanding perceptions of international agency to include firms, non-governmental organizations (NGOS) and other actors' who increasingly intervene in diplomatic activities. ${ }^{7}$ Defined as non-sovereign entities that are able to exercise economic, political or social power and influence on the national or international levels, ${ }^{8}$ non-state actors increasingly influence political discourse and agenda-setting ${ }^{9}$ by participating in global networks, mobilising resources for addressing social and political issues and directly engaging with civic societies from various countries. ${ }^{10}$

Addressing this global rise of non-state diplomacy, Brian Hocking et al. identify a post-globalist approach in diplomacy that provides a space for 'diplomacies pursued by states, international organizations and non-state actors [...] integrated into the complex, multi-faceted patterns of world politics.'11 Within Stuart Murray's taxonomy of diplomacy scholarship, ${ }^{12}$ this 'postglobalist' perspective can be situated in the Innovative School of diplomacy studies, which acknowledges a complex co-existence on the global stage of various types of actors, ranging from terrorist groups to non-governmental organisations, and civil-society activists to transnational business corporations. ${ }^{13}$ Based on these premises, this special issue of The Hague Journal of Diplomacy deepens our understanding of interactions between state and non-state actors by focusing on cases in which these interrelations take different forms

6 Teresa LaPorte, "The Impact of "Intermestic" Non-State Actors on the Conceptual Framework of Public Diplomacy', The Hague Journal of Diplomacy, vol. 7, no. 4 (2012), pp. $441-458$, at p. 442.

7 John Robert Kelley, 'The New Diplomacy: Evolution of a Revolution', Diplomacy \& Statecraft, vol. 21 (2010), pp. 286-305, at p. 287.

8 LaPorte, "The Impact of "Intermestic" Non-State Actors on the Conceptual Framework of Public Diplomacy'.

9 Bas Arts, Math Noortmann and Bob Reinalda, Non-State Actors in International Relations (Aldershot: Ashgate, 2001).

10 Muhittin Ataman, 'The Impact of Non-State Actors on World Politics: A Challenge to Nation-States', Alternatives: Turkish Journal of International Relations, vol. 2, no. 1 (2003).

11 Brian Hocking, Jan Melissen, Shaun Riordan, and Paul Sharp, Integrative Diplomacy in the 21st Century (The Hague: Netherlands Institute of International Relations 'Clingendael', 2012), p. 18.

12 Murray, 'Consolidating the Gains Made in Diplomacy Studies'.

13 Peter Spiro, 'Constraining Global Corporate Power: A Short Introduction', Vanderbilt Journal of Transnational Law, vol. 46 (2013), pp. 1101-1118, at p. 1103. 
and shapes because of a number of 'environmental' contingencies or cultural and political depositions that exist in countries beyond the Western world.

While non-Western countries occasionally provide an empirical platform for explorations of non-state forms of public diplomacy, ${ }^{14}$ current academic literature predominantly concentrates on cases of Western democracies. The dominant stream in diplomatic scholarship specifically stresses that democratic systems allow an increasing acceleration of political and economic instruments for a progressive development of non-state diplomacy, while the challenging regulative and legislative climates in less-democratic societies have a low potential to accommodate the political or economic autonomy of non-state initiatives because of lack of 'democratic legitimacy' or 'internal democracy' 15

In most cases, the theoretical tradition in research on non-state diplomacy frequently equates 'non-state' with more democratic and open systems, in which actors can enjoy access to social and economic resources to acquire a certain diplomatic 'legitimacy'. This legitimacy is based on actors' capabilities to exercise diplomacy, as opposed to diplomacy of status. ${ }^{16}$ Michael Edwards defines non-state legitimacy as 'the right to be and to do something in society; a sense that an organisation is lawful, proper, admissible and justified in doing what it does and saying what it says, and that it continues to enjoy the support of an identifiable constituency'. ${ }^{17}$ Based on a large body of diplomacy literature that explores sources of non-state legitimacy, four important components of actors' capabilities are recurrent across different scholars, including expertise, reputation, credibility, and resources and alliances.

14 See Ian Hall, 'India's New Public Diplomacy: Soft Power and the Limits of Government Action', Asian Survey, vol. 52, no. 6 (2012), pp. 1089-1110; György Szondi, 'Central and Eastern European Public Diplomacy: A Transitional Perspective on National Reputation Management', in Nancy Snow and Philip M. Taylor (eds), Routledge Handbook of Public Diplomacy (New York, NY: Routledge, 2009), pp. 292-313; Shay Attias, 'Israel's New Peer-to-Peer Diplomacy', The Hague Journal of Diplomacy, vol. 7, no. 4 (2012), pp. 473-482.

15 Shaun Riordan, 'The New International Security Agenda and the Practice of Diplomacy', in Andrew F. Cooper, Brian Hocking and William Maley (eds), Global Governance and Diplomacy: Worlds Apart? (Basingstoke: Palgrave Macmillan, 2008), pp. 135-144, at p. 140.

16 John Robert Kelley, Agency Change: Diplomatic Action beyond the State (Lanham, MD: Rowman \& Littlefield, 2014).

17 Michael Edwards, 'International Development NGOs: Agents of Foreign Aid or Vehicles of International Cooperation?', Non-Profit and Voluntary Sector Quarterly, vol. 28 (1999), pp. $25-37$, at p. 26 . 
Expertise usually refers to an organisation's professional or specialised knowledge, ${ }^{18}$ coupled with a unique adaptability to fast-paced globalising conditions by employing innovative solutions that allow the non-state actor to outperform state agents in addressing urgent problems. ${ }^{19}$ Such an expertise leads to an organisation's strong reputation ${ }^{20}$ to engage in diplomacy by serving the needs of its key constituency, ${ }^{21}$ as well as through representation of interests and advocacy on behalf of the main stakeholders. ${ }^{22}$ Trust or credibility means an organisation's ability to establish long-term trustworthy relationships with key constituencies, ${ }^{23}$ while building resources and alliances on the global stage to strengthen its institutional financial sustainability and allow economic autonomy from government money. ${ }^{24}$

These findings lead to unintentional assumptions that narrow down the definition of a 'non-state' actor, which is frequently described as a nongovernmental organisation that adheres to 'progressive' principles of Western democracy and liberalism. While acknowledging these propositions in public diplomacy literature, the articles in this special issue of The Hague Journal of Diplomacy depart from the academic discourse that tends to equate 'non-state actorness' with a certain form of a more 'reformist' or democratic development. Instead, the case studies from Russia and China broaden the semantic field of the term 'non-state diplomacy' by breaking down the 'narrative of progress' or 'a progression towards a Western-styled, "liberalised", "marketised",

18 See Mark Leonard (ed.), Public Diplomacy (London: Foreign Policy Centre, 2002); Ole Jacob Sending, Vincent Pouliot and Iver Neumann, 'The Future of Diplomacy: Changing Practices, Evolving Relationships', International Journal, vol. 66, no. 3 (2011), pp. 527-542.

19 Lucian Jora, 'New Practices and Trends in Cultural Diplomacy', Political Science and International Relations, vol. 10, no. 1 (2013), pp. 43-52.

20 See Deborah Avant, Martha Finnemore, and Susan Sell (eds), Who Governs the Globe? (Cambridge: Cambridge University Press, 2010).

21 See LaPorte, 'The Impact of "Intermestic" Non-State Actors'; Alan Henrikson, 'Sovereignty, Diplomacy, and Democracy: The Changing Character of International Representation from State to Self', Fletcher Forum of World Affairs, vol. 37, no. 3 (2013), pp. 111-140.

22 See Manuel Castells, 'The New Public Sphere: Global Civil Society, Communication Networks, and Global Governance', The ANNALS of the American Academy of Political and Social Science, vol. 616, no. 1 (2008), pp. 78-93.

23 See Rhonda Zaharna, 'Battles to Bridges: US Strategic Communication and Public Diplomacy after 9/11', in Donna Lee and Paul Sharp (eds), Studies in Diplomacy and International Relations (Basingstoke: Palgrave Macmillan, 2010); Shaun Riordan, 'The New International Security Agenda and the Practice of Diplomacy', in Andrew F. Cooper, Brian Hocking and William Maley (eds), Global Governance and Diplomacy: Worlds Apart? (Basingstoke: Palgrave Macmillan, 2008).

24 See Bob Reinalda and Bertjan Verbeek, 'Theorizing Power Relations between NGOs, Intergovernmental Organizations and States', in Arts et al. (eds), Non-State Actors in International Relations, pp. 145-158. 
"globalised", "democratised"' system. ${ }^{25}$ Acknowledging that non-Western societies 'build understanding of international relations (IR) based on their own histories and social theories, ${ }^{26}$ this special issue offers insightful case studies that help to theorise further non-state governance in contemporary diplomacy.

\section{Defining 'Non-Western'}

For purposes of this project, non-Western countries are defined as those outside North America, Europe, Australia and New Zealand. The range of articles here includes emerging scholarship by early-career researchers of contemporary diplomacy that represent such countries as China, Russia and Turkey. Because their perspectives have been formed by intimate knowledge of the inner workings of these places, more precise and authentic views are added to the debate on non-state forms of governance that are rapidly developing in parallel with traditional diplomacies outside of the Western world. Recognising the risk of using dichotomous opposition of 'Western' versus 'non-Western', ${ }^{27}$ it is important to clarify that the umbrella term 'non-Western perspectives' is not used to reinforce or reflect the 'West versus the rest' bipolar view of the world. Kimberly Hutchings brilliantly breaks down the logical traps within these binary classifications:

The terminology of 'West'/'non-West' is over-determined by the ways in which it has been used to mark distinctions. [...] If 'West' and 'non-West' are ways of life, then is 'West' urban and 'non-West' rural? Is 'West' secular and 'non-West' religious? [...] If 'West' and 'non-West' refer to different institutions and regimes, then is 'West' democratic and 'non-West' authoritarian? Or is 'West' competitive and 'non-West' cooperative? ${ }^{28}$

While the use of hierarchical binary oppositions has long been outmoded as an analytical tool, undeniably the tendency remains, with structural biases

25 Donald J. Puchala, 'Some Non-Western Perspectives on International Relations', Journal of Peace Research, vol. 34, no. 2 (1997), pp. 129-134, at p. 133.

26 See Puchala, 'Some Non-Western Perspectives on International Relations', p. 29o; Acharya Amitav and Barry Buzan, 'Why Is There No Non-Western International Relations Theory? An Introduction', International Relations of the Asia Pacific, vol. 7, no. 3 (2007), pp. 287-312. Kimberly Hutchings, 'Dialogue between Whom? The Role of the West/Non-West Distinction in Promoting Global Dialogue in IR', Millennium: Journal of International Studies, vol. 39, no. 3 (2011), pp. 639-647.

28 Hutchings, 'Dialogue between Whom?, p. 646. 
fuelled by the dominant players in the world of diplomacy, all the way down to the memoirs of those who toiled on their behalf. The umbrella term 'nonWestern perspectives' mainly serves to depart from established pathways in the research of non-state diplomacy and decentre the scholarship towards the geographical regions previously neglected or underexplored. Furthermore, staking out the 'non-Western' concept is convenient in that it attracts attention, it draws clear boundaries, and it effectively creates a space for a thoughtprovoking dialogue and even a debate.

It is also important to stress that our aim is not necessarily to displace theoretical foundations of the study of non-diplomacy originated from Western ideas and experiences. Naaem Inayatullah and David Blaney rightfully warned that moving 'beyond the West' does not mean to reject, but to open up established canons in scholarship for a 'rediscovery and reimagination.' ${ }^{29}$ Instead, the issue prolifically engages with the existing academic literature as an important point of departure. It builds upon the diplomacy scholarship to establish a space for exploratory research to conceptualise alternative forms and structures of non-state governance that have previously been unexposed in an academic enquiry.

\section{Theorising Non-state Diplomacy in Non-Western Contexts}

The articles in this special issue of The Hague Journal of Diplomacy expand existing typologies of non-state diplomacy, ranging from complete co-option of non-state agencies by national governments ${ }^{30}$ to cases indicative of 'mimicking state diplomacy'31 to an emergence of new diplomatic conduct and operations, or what has been termed 'polylateral norms' leading to a less statecentric and hierarchical system of governance in the international arena with asymmetric socialisation of non-state norms. ${ }^{32}$ The expansion here takes place in the form of two key trends: cooperative diplomacy; and adversarial diplomacy.

\footnotetext{
29 Naaem Inayatullah and David L. Blaney, International Relations and the Problem of Difference (London: Routledge, 2004), p. 16.

3o Geoffrey Wiseman, 'Bringing Diplomacy Back In: Time for Theory to Catch Up with Practice', International Studies Review, vol. 13 (2011), pp. 709-728, at p. 712.

31 Fiona McConnell, Terri Moreau and Jason Dittmer, 'Mimicking State Diplomacy: The Legitimizing Strategies of Unofficial Diplomacies', Geoforum, vol. 43 (2012), pp 804-814.

32 See Barry Buzan, From International to World Society? (Cambridge: Cambridge University Press, 2004); and Wiseman, 'Bringing Diplomacy Back In'.
} 
In regard to cooperative diplomacy, several case studies presented here go beyond a binary polarisation of state versus non-state actorness. They identify forms of hybrid structures or certain forms of partnerships that do not necessarily presuppose co-option or mimicking, or do not create new hierarchies diminishing the role of the state. In particular, Li, Xuefei Chen and Elizabeth Hanson, and Natalia Grincheva, offer an empirical exploration of cases from China $^{33}$ and Russia ${ }^{34}$ to highlight nuances of the 'pluralisation' processes in contemporary diplomacy, ${ }^{35}$ which might not be so visible in Western contexts, shaped by a stronger differentiation and formal acceptance of roles among various agencies involved in diplomacy. These cases identify important forms of cooperative, hybrid diplomacy, revealing that more-authoritarian regimes such as Russia and China can also provide an enabling context. In this unique environment, non-state forms of governance can not only survive, but also develop and even thrive. These examples help us to theorise non-state diplomacy beyond the traditional frame of democratic governance. Both examples expose the existence of autonomous private diplomatic actors and initiatives in countries that are frequently criticised for a lack of democratic legitimacy and for shaping only one-way propaganda-type diplomatic communications in the world arena.

Cases exploring adversarial diplomacy reveal conflicting contexts defined either by elite pressure, social disintegration, collective alienation from central governments, or the formation of oppositional political parties that 'take on issues "no longer coterminous" with national interests' and foreign policy agenda. ${ }^{36}$ Anna Popkova and Nur Uysal offer illuminating cases from Russia and Turkey of adversarial, oppositional non-state actors that take an active role in the global arena to challenge their states by communicating directly with foreign publics. Both cases present compelling evidence of competing forms of state versus non-state governance that rapidly develop beyond the Western world and reshape established notions of legitimacy and representation in contemporary diplomacy. More importantly, these examples add another

33 Li Li, Xuefei Chen and Elizabeth C. Hanson, 'Private Think Tanks and Public-Private Partnerships in Chinese Public Diplomacy', The Hague Journal of Diplomacy, vol. 14, no. 3 (2019), this issue.

34 Natalia Grincheva, 'Beyond State versus Non-State Dichotomy: The State Hermitage Museum as a Russian Diplomacy "Hybrid”, The Hague Journal of Diplomacy, vol. 14, no. 3 (2019), this issue.

35 Cornago. Plural Diplomacies.

36 See Kelley, 'The New Diplomacy'; Geoffrey Wiseman (ed.), Isolate or Engage: Adversarial States, US Foreign Policy, and Public Diplomacy (Stanford, CA: Stanford University Press, 2015). 
level of complexity to the category of 'non-Western', as both demonstrate the power of traditionally Western liberal values of democratic openness and cooperation to shape the political orientation, social activism and international agendas either of political oppositions to a state government or to diasporic communities abroad.

Drawing on new insights, both cooperative and adversarial trends in nonstate diplomacy expose domestic complexities in relation to geopolitical implications in which institutional and political dynamics facilitate and complicate relations between governments and diverse social and political actors, ranging from domestic NGOs to diasporic groups.

In conclusion, it is important to point out that there are two oppositional forces that give birth to these new forms of non-state diplomacy in nonWestern countries. On the one hand, unique relationships among state and non-state actors emerge as an important part of historical contexts within socio-political national environments. These historical parallels open new avenues for conceptualising non-state diplomacy outside the Western world. As Donald Puchala insightfully points out, "Western categories such as "States", for example, are not very important in non-Western thinking about world affairs', in contrast to 'forces, movements, parties, peoples, cultures, and civilizations. ${ }^{37}$ This proves to be true in the context of Russian and Chinese public diplomacy, which takes root in unique state versus non-state relationships that historically have emerged predominantly within national borders for generations.

Alternatively, each author correctly accounts for the power of globalisation and new means of communication technologies that are enabling new forms of non-state governance in non-Western contexts. Social networks, digital technologies and increasing neo-liberal forces are empowering the rapid growth of private actors. These actors bring in a wider plurality of voices and identities to the world stage, as well as facilitate a greater variety of institutional mediations that constitute the global diplomatic landscape. Expanding cooperative and adversarial forms of contemporary non-state diplomacy, this special issue of The Hague Journal of Diplomacy opens a window to a less exposed, discussed and theorised empirical framework constituting non-Western contexts. We hope that it will incite and encourage future productive and focused explorations of contemporary non-state diplomacy rapidly emerging in the Asia-Pacific region, Middle East, Africa and South America, which is currently lacking strong representation in the academic scholarship.

37 Puchala, 'Some Non-Western Perspectives on International Relations'. 


\section{Natalia Grincheva}

is a Research Fellow at the Research Unit in Public Cultures at the University of Melbourne. The holder of several prestigious international academic awards, including a Fulbright (2007-2009), Quebec Fund (2011-2013), Australian Endeavour (2012-2013) and Soros research grant (2013-2014), she has travelled the world to conduct research on digital diplomacy. Focusing on new museology and social-media technologies, she has successfully implemented several research projects on the 'diplomatic' uses of new media by the largest museums in North America, Europe and the Asia-Pacific region. Her most recent publication is a monograph, Global Trends in Museum Diplomacy (London: Routledge, July 2019).

\section{Robert Kelley}

is an Assistant Professor at the School of International Service, American University, in Washington, DC, where from 2012-2013 he directed the Intercultural Management Institute, setting a new course for the training and consulting of diplomatic corps around the world. Prior to entering academia, he worked as an international business consultant and, subsequently, at the US Department of State. He holds a Ph.D. in International Relations from the London School of Economics, and later developed his research while a Hayward R. Alker Post-Doctoral Fellow at the University of Southern California (USC) Center for International Studies. Kelley's research lies at the intersection of culture and politics; he specialises in the study of civic responsibility on the global level, global citizenship in the diplomatic arena, and the citizen as a legitimate global actor. His latest book is Agency Change: Diplomatic Action beyond the State (Lanham, MD: Rowman \& Littlefield, 2014). 